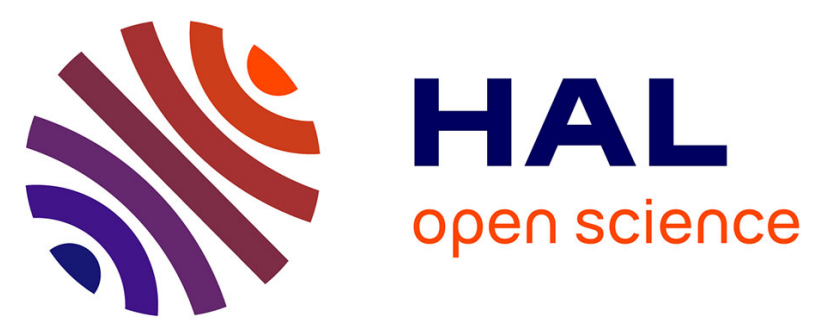

\title{
Structural equivalence between direct residuals based on parity space and indirect residuals based on unknown input observers
}

\author{
Walter Nuninger, Frédéric Kratz, José Ragot
}

\section{- To cite this version:}

Walter Nuninger, Frédéric Kratz, José Ragot. Structural equivalence between direct residuals based on parity space and indirect residuals based on unknown input observers. 3th IFAC Symposium on Fault Detection, Supervision and Safety of Technical Processes, SAFEPROCESS 1997, Aug 1997, Hull, United Kingdom. pp.462-467. hal-00971516

\section{HAL Id: hal-00971516 https://hal.science/hal-00971516}

Submitted on 3 Apr 2014

HAL is a multi-disciplinary open access archive for the deposit and dissemination of scientific research documents, whether they are published or not. The documents may come from teaching and research institutions in France or abroad, or from public or private research centers.
L'archive ouverte pluridisciplinaire HAL, est destinée au dépôt et à la diffusion de documents scientifiques de niveau recherche, publiés ou non, émanant des établissements d'enseignement et de recherche français ou étrangers, des laboratoires publics ou privés. 


\title{
STRUCTURAL EQUIVALENCE BETWEEN DIRECT RESIDUALS BASED ON PARITY SPACE AND INDIRECT RESIDUALS BASED ON UNKNOWN INPUT OBSERVERS.
}

\author{
Walter NUNINGER, Frédéric KRATZ, José RAGOT
}

\author{
Centre de Recherche en Automatique de Nancy - CNRS URA 821 \\ Institut National Polytechnique de Lorraine \\ 2, Avenue de la Forêt de Haye. 54516 Vandoeuvre-lès-Nancy Cedex, France \\ Tél. : (33) 383595959 - Fax : (33) 383595684 \\ E-mail : \{ wnuninge,fkratz,jragot\}@ensem.u-nancy.fr
}

\begin{abstract}
In order to solve the fault detection and isolation problem, a diagnostic procedure is used. This procedure is composed of two steps: residuals generation followed by their evaluation within decision functions. Many ways have been developed to generate residuals. Among them, we quote the well known parity space approach and the observer based approach. These methods are known to produce structural equivalent residuals. As a consequence, one wonders which method to use in order to design a more robust on-line detection system. Besides, unknown input observers are known to be helpful, within Generalised Observer Schemes, to improve robustness with respect to systems uncertainties. Then, it is important to know if this equivalence is still true for residuals based on unknown input observers. So the goal of this paper is to give theorems so that answers to the previous interrogations could be given and discussed.
\end{abstract}

Key words: Redundancy, fault detection, fault isolation, observers, unknown input, parity space, robustness.

\section{INTRODUCTION}

Nowadays, fault diagnosis is an important field of research because of the increasing complexity of processes. Indeed, control systems require failures to be detected and isolated and further taken into account in order to maintain the performances required. Many surveys on design methods for the diagnostic procedure were done by Iserman (1976), Frank (1990, 1993), Gertler (1991) and Patton (1994). In the past decade, the trend has been the development of analytical redundancy based methods rather than massive redundancy based approaches. These methods generate a signal significant of the fault. This signal that contains information about the failure, is called a residual. Such a residual is defined so that it is statistically close to zero when there is no failure and quite differs from this value otherwise. It is important to note that all these methods require a model of the system behaviour. Such a model is submitted to uncertainties like measurement noise and parameter (and even structure) variations. Depending on the assumptions supposed for the design of the detection system, these disturbances can lead to false alarms or no detection that degrade the performances. This problem is referred in the literature (Frank, 1990) as the robustness proprieties of the diagnostic procedure with respect to disturbances. Robustness is a degree of performance. It is then obvious that this degree is the result of a compromise between distinct performance criteria such as, for instance, both minimal no detection and false alarm rates. Among the techniques used for residual generation, two groups of techniques are presented: the direct generation based on parity space equation and 
the non direct generation that provides a residual based on state estimation. In that case, the simplest residual performed is the state estimation error, i.e. the comparison between the measured data and its estimation.

In the literature, the reason to prefer one technique (direct) to the other (indirect) mostly depends on the habit rather than more scientific criteria. As presented previously, criteria considering the easier way to implement the method and/or the more robust residual generated should be worthwhile. The structural equivalence of the residual of both methods is well known. Indeed, Patton and Chen (1991) recall that parity space leads to reliable FDI scheme. They stress on the fact that even though their potential robustness was studied, less work has been done to show the powerful correspondence existing between both techniques. Nevertheless, Frank and Wünnenberg (1989) and Frank (1990) pointed out that under certain conditions both residuals were equivalent within a choice of the observer gain to get the same proprieties on the estimation error. This result was proved afterwards by Magni and Mouyon (1991). Several authors as, Frank and Wünnenberg (1989), Wünnenberg (1990), Gertler (1991), Staroswiesky (1991) and Frank (1993) evidenced that parity space approach leads to certain types of observer structures and is therefore structurally equivalent. Anyway, no results have been given with regard to unknown input observers, nor about the robust aspect.

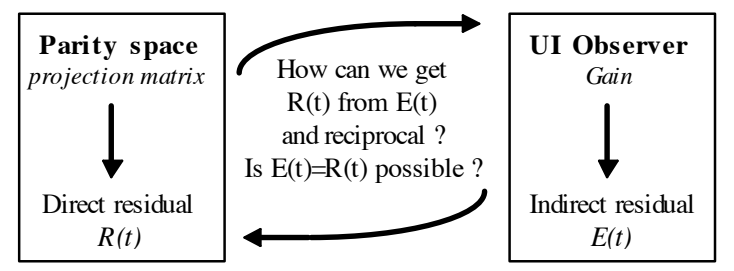

Fig. 1: Problem illustration

The goal of this paper is illustrated in Fig. 1. Its relevance is first, to consider unknown input observer, and second, to present the results into the lemma and theorem format. Some attention to this case has already been made by Nuninger et al. (1996), but at that time only one theorem was proved, i.e. if an unknown input observer can be found to generate the residual as the estimation error, then one can construct the projection matrix for the direct approach and get the structure of the parity space based dual residual. Here, the reciprocal part of this theorem is proved and its implications are discussed.

This paper is organised as follows. First, the problem formulation is presented. Second, from (Nuninger, et al., 1996), both the generation scheme of analytical redundancy equations and the indirect residual generation procedure, based on unknown input observer, are quickly recalled. In the third part, theorems and demonstrations are given to get one residual from another. Finally, the consequences implied by the previous theorems, for the design of a robust on-line diagnostic procedure, are discussed.

\section{PROBLEM FORMULATION}

Let us consider the linear time-invariant system subject to disturbances:

$$
\begin{aligned}
& x(t)=A x(t)+B u(t)+H v(t) \\
& y(t)=C x(t)+D u(t)+F v(t)
\end{aligned}
$$

where $\mathrm{x} \in \mathrm{R}^{\mathrm{n}}$ is the state vector, $\mathrm{u} \in \mathrm{R}^{\mathrm{r}}$ the control input, $\mathrm{y} \in \mathrm{R}^{\mathrm{p}}$ the measured output vector and $\mathrm{v} \in \mathrm{R}^{\mathrm{q}}$ the disturbance vector which components are unknown functions of the time. All the matrices are of appropriate dimensions and of real constant components. Note that this representation can describe a great number of systems such as uncertain parameter systems or singular systems for instance. Define the following assumptions:

Hypothesis 1: $\mathrm{C}$ is a full row rank matrix.

Hypothesis 2: there is more measurements than unknown inputs $(p>q)$.

Hypothesis 3: $\mathrm{H}$ is a full column rank matrix

Hypothesis 4: $\mathrm{F}$ is a full column rank matrix

Assumption 1 implies that there is no more massive redundancy in (1.b). This assumption is not restrictive as a singular value decomposition of $\mathrm{C}$ can always be performed so that massive and analytical redundancy are driven apart. Assumption 2 is therefore a sufficient condition to provide analytical redundancy. Assumptions 3 and 4 are not restrictive either as it only means that the unknown inputs have independent influence on the state and the output respectively. If this is not the case, a simple basis transaction can transform the system so that hypothesis 3 or 4 are true.

Consider system (1) that only satisfies hypothesis 1 and 2 . For such a system, reduced equations (3) can always be found thanks to a singular value decomposition (2) of F. Thanks to the formulation (3), the part independent of the unknown inputs has been driven apart in the measurement equation.

$$
\mathrm{F}=\mathrm{U}\left(\begin{array}{cc}
\mathrm{R} & 0 \\
0 & 0
\end{array}\right) \mathrm{V}^{\mathrm{T}}
$$

where $\mathrm{U}$ and $\mathrm{V}$ are of dimension pxp and qxq respectively and $\mathrm{m}=\operatorname{rank}(\mathrm{R}) \leq \inf (\mathrm{p}, \mathrm{q})=\mathrm{q}($ Hyp. 2$)$,

$$
\begin{aligned}
& x(t)=A_{1} x(t)+B_{1} u(t)+H_{1} y_{1}(t)+H_{2} v_{2}(t) \\
& y_{1}(t)=C_{1} x(t)+D_{1} u(t)+v_{1}(t) \\
& y_{2}(t)=C_{2} x(t)+D_{2} u(t)
\end{aligned}
$$


where $\mathrm{v}_{1} \in \mathrm{R}^{\mathrm{m}}, \mathrm{v}_{2} \in \mathrm{R}^{\mathrm{q}-\mathrm{m}}, \mathrm{y}_{1} \in \mathrm{R}^{\mathrm{m}}, \mathrm{y}_{2} \in \mathrm{R}^{\mathrm{p}-\mathrm{m}}$ and the following definition of the matrices an vectors:

$$
\begin{aligned}
& \Sigma=\left(\begin{array}{ll}
\mathrm{R} & 0 \\
0 & \mathrm{I}
\end{array}\right), \quad \mathrm{V}^{\mathrm{T}} \mathrm{v}=\left(\begin{array}{c}
\mathrm{v}_{1} \\
\mathrm{v}_{2}
\end{array}\right), \quad \Sigma^{-1} \mathrm{U}^{\mathrm{T}} \mathrm{y}=\left(\begin{array}{l}
\mathrm{y}_{1} \\
\mathrm{y}_{2}
\end{array}\right), \\
& \Sigma^{-1} \mathrm{U}^{\mathrm{T}} \mathrm{C}=\left(\begin{array}{l}
\mathrm{C}_{1} \\
\mathrm{C}_{2}
\end{array}\right), \quad \Sigma^{-1} \mathrm{U}^{\mathrm{T}} \mathrm{D}=\left(\begin{array}{c}
\mathrm{D}_{1} \\
\mathrm{D}_{2}
\end{array}\right), \quad \mathrm{A}_{1}=\mathrm{A}-\mathrm{H}_{1} \mathrm{C}_{1}, \\
& \mathrm{~B}_{1}=\mathrm{B}-\mathrm{H}_{1} \mathrm{D}_{1} \text { and } \mathrm{HV}=\left(\begin{array}{ll}
\mathrm{H}_{1} & \mathrm{H}_{2}
\end{array}\right) .
\end{aligned}
$$

Remark 1. Within our hypothesis 1 and 2, propriety (4) can easily be proved, i.e. there is no direct redundancy in (3.c) as any matrix built from rows of $\mathrm{C}$ is also a full row rank matrix. Under hypothesis 3, (5) is also true. Finally, equation (3.b) can provide the estimation of some unknown inputs if the system state reconstructability is assumed.

$$
\begin{aligned}
& \operatorname{rank}\left(\left[\begin{array}{l}
\mathrm{C}_{1} \\
\mathrm{C}_{2}
\end{array}\right]\right)=\mathrm{p} \\
& \operatorname{rank}\left(\left[\begin{array}{ll}
\mathrm{H}_{1} & \mathrm{H}_{2}
\end{array}\right]\right)=\mathrm{q}
\end{aligned}
$$

It is important to note that hypothesis 1,2 and 3 stand for the necessary and sufficient condition for the existence of an unknown input observer for system (1): $\operatorname{rank}(\mathrm{CH})=\operatorname{rank}(\mathrm{H})=\mathrm{q}$ (Darouach, et al., 1994).

Remark 2. Within assumption 4, the singular value decomposition of $\mathrm{F}$ leads to (6) with $\mathrm{m}=\operatorname{rank}(\mathrm{R})=\mathrm{q}$. This implies that the dimension of $v_{2}$ is null. So, $v_{1}$ is defined by $\mathrm{V}^{\mathrm{T}} \mathrm{v}=\mathrm{v}_{1}$ and $\mathrm{v}_{2}$ does not appear in the equations (3) anymore. As a consequence, the matrix $\mathrm{H}_{2}$ does not appear either. Indeed, $\mathrm{HV}=\mathrm{H}_{1}$.

$$
\mathrm{F}=\mathrm{U}\left(\begin{array}{c}
\mathrm{R} \\
0_{(\mathrm{n}-\mathrm{q}), \mathrm{q}}
\end{array}\right) \mathrm{V}^{\mathrm{T}}
$$

\section{RESIDUALS GENERATIONS}

\subsection{Direct residual generation}

Lemma 1. Consider system (1) of reduced form (3) that satisfies hypothesis 1 and 2 . Then a parity space, defined by the projection matrix :

$$
\Omega(\mathrm{s})=\left[\begin{array}{lll}
\Omega_{3}(\mathrm{~s}) \mathrm{C}_{2}\left(\mathrm{sI}_{\mathrm{n}}-\mathrm{A}_{1}\right)^{-1} & 0_{(\mathrm{n}+\mathrm{q}), \mathrm{m}} & \Omega_{3}(\mathrm{~s})
\end{array}\right]
$$

of dimension $(n+q) x(n+p)$ exists if and only if :

(i) $\Omega_{3}(\mathrm{~s}) \mathrm{C}_{2}\left(\mathrm{sI}_{\mathrm{n}}-\mathrm{A}_{1}\right)^{-1} \mathrm{H}_{2}=[0]_{(\mathrm{n}+\mathrm{q})(\mathrm{q}-\mathrm{m})}$

$$
\Leftrightarrow \text { (ii) matrix }\left(\begin{array}{cc}
\mathrm{sI}_{\mathrm{n}}-\mathrm{A}_{1} & -\mathrm{H}_{2} \\
\mathrm{C}_{2} & 0
\end{array}\right) \text { is full column rank }
$$

or under the additive hypothesis 4 , if and only if :

(iii) the pair $\left(A_{1}, C_{2}\right)$ is observable

Proof. Redundancy equations are simply obtained by elimination of the unknown variables, $\mathrm{x}$ and $\mathrm{v}$, in equation (3). First, the Laplace transform is applied to equation (3) in order to separate the known data ( $\mathrm{u}$ and $\mathrm{y}$ ) from the unknown variables. Second, a projection matrix, $\Omega(\mathrm{s})=\left[\begin{array}{lll}\Omega_{1}(\mathrm{~s}) & \Omega_{2}(\mathrm{~s}) & \Omega_{3}(\mathrm{~s})\end{array}\right]$, of dimension $(n+q) x(n+p)$ is used to get the redundancy equations:

$\Omega(s)\left(\begin{array}{ccc}B_{1} & H_{1} & 0 \\ -D_{1} & I_{m} & 0 \\ -D_{2} & 0 & I_{p-m}\end{array}\right)\left(\begin{array}{c}u(s) \\ y_{1}(s) \\ y_{2}(s)\end{array}\right)=[0]_{n+q), 1}$

Note that $\Omega$ (s) satisfies:

$\Omega(s)\left(\begin{array}{ccc}\mathrm{sI}_{\mathrm{n}}-\mathrm{A}_{1} & 0 & -\mathrm{H}_{2} \\ \mathrm{C}_{1} & \mathrm{I}_{\mathrm{m}} & 0 \\ \mathrm{C}_{2} & 0 & 0\end{array}\right)=[0]_{(\mathrm{n}+\mathrm{q})(\mathrm{n}+\mathrm{q})}$

which is the constraint on the projection matrix. This constraint can be expressed so that the projection matrix $\Omega(\mathrm{s}$ ) is defined by (7.a) with the constraint (7.b) satisfied by $\Omega_{3}(\mathrm{~s})$ of dimension $(\mathrm{n}+\mathrm{q}) \mathrm{x}(\mathrm{p}-\mathrm{m})$. A solution exists if and only if (ii) is true, i.e. :

$\forall \mathrm{s} \in \mathrm{C}, \operatorname{Re}(\mathrm{s})>0 \operatorname{rank}\left(\begin{array}{cc}\mathrm{sI}_{\mathrm{n}}-\mathrm{A}_{1} & -\mathrm{H}_{2} \\ \mathrm{C}_{2} & 0\end{array}\right)=\mathrm{n}+\mathrm{q}-\mathrm{m}$

Under hypothesis 4, a simpler form of (9) is given (cf. remark 2) so that constraint (7.b) has not to be satisfied anymore. As a consequence, the necessary and sufficient condition for the parity space is reduced to (iii). In this case any matrix $\Omega_{3}(\mathrm{~s})$ of dimension $(n+q) x(p-m)$ can be chosen.

In both cases, Nuninger et al. (1996) demonstrated that (8) leads to the simplified form of the direct residual $\mathrm{r}(\mathrm{s})$ :

$$
\begin{array}{r}
r(s)=-\Omega_{3}(s)\left\{C_{2}\left(s_{n}-A_{1}\right)^{-1} B_{1}+D_{2}\right] u(s) \\
\left.+C_{2}\left(s_{n}-A_{1}\right)^{-1} H_{1} y_{1}(s)-y_{2}(s)\right\}
\end{array}
$$

and that the search of $\Omega_{3}(\mathrm{~s})$ was reduced to the search of the kernel of a binomial matrix. Note that this matrix can be chosen of minimal degree. These results are based on Gantmacher's theory (Gantmacher, 1977). In practice, $\Omega_{3}(\mathrm{~s})$ is obtained within the use of Maple. It should be noted that the residual (10) is sensitive to both sensor and actuator faults.

\subsection{Indirect residual generation}

On the other hand, implicit redundancy equations can be generated as the difference between the measured output and the estimated output based on an unknown input observer of the state defined by:

$$
\begin{aligned}
& \mathrm{z}(\mathrm{t})=\mathrm{Nz}(\mathrm{t})+\mathrm{L}_{1} \mathrm{y}_{1}(\mathrm{t})+\mathrm{L}_{2} \mathrm{y}_{2}(\mathrm{t})+\mathrm{Gu}(\mathrm{t}) \\
& \hat{\mathrm{x}}(\mathrm{t})=\mathrm{z}(\mathrm{t})-\mathrm{V}_{1} \mathrm{y}_{1}(\mathrm{t})-\mathrm{V}_{2} \mathrm{y}_{2}(\mathrm{t})+\mathrm{Mu}(\mathrm{t})
\end{aligned}
$$

where $z(t)$ is of dimension $n$ and $\hat{x}(t)$ denotes the state estimation of size $n$. 
Lemma 2. Consider system (1) of reduced form (3) that satisfies hypothesis 1 and 2 . Then the estimation error, $\varepsilon(\mathrm{t})=\hat{\mathrm{x}}(\mathrm{t})-\mathrm{x}(\mathrm{t})$, based on the unknown input observer (11) tends asymptotically to zero if and only if the following relations are satisfied:

$$
\begin{aligned}
& \mathrm{N} \text { stable } \\
& \mathrm{V}_{1}=[0]_{n, m} \\
& \mathrm{PH}_{2}=[0]_{\mathrm{n}-\mathrm{m}} \\
& \mathrm{M}=\mathrm{V}_{2} \mathrm{D}_{2} \\
& \mathrm{~L}_{1}=\mathrm{PH}_{1} \\
& \mathrm{P}=\mathrm{I}_{\mathrm{n}}+\mathrm{V}_{2} \mathrm{C}_{2} \\
& \mathrm{~L}_{2} \mathrm{C}_{2}=\mathrm{PA}_{1}-\mathrm{NP} \\
& \mathrm{G}=\mathrm{PB}_{1}-\mathrm{L}_{2} \mathrm{D}_{2}
\end{aligned}
$$

Proof. (Nuninger, et al., 1996) Note that the N stability problem (12.a) is reduced to an eigenvalue assignment problem for the observable pair $\left(\mathrm{PA}_{1}, \mathrm{C}_{2}\right)$ within the use of a gain

Lemma 3. Consider system (1) of reduced form (3) that satisfies hypothesis 1,2 and 3 . Then for a square matrix $\mathrm{P}$ of rank $\mathrm{n}-(\mathrm{q}-\mathrm{m})$, the unknown input observer (11) exists if and only if:

(i) the pair $\left(A_{1}, C_{2}\right)$ is detectable (observable)

$\Leftrightarrow$ (ii) $\operatorname{rank}\left(\begin{array}{c}\mathrm{sP}-\mathrm{PA}_{1} \\ \mathrm{C}_{2}\end{array}\right)=\mathrm{n} \quad \forall \mathrm{s} \in \mathrm{C}, \operatorname{Re}(\mathrm{s})>0$

$\Leftrightarrow$ (iii) matrix $\left(\begin{array}{cc}\mathrm{sI}_{\mathrm{n}}-\mathrm{A}_{1} & -\mathrm{H}_{2} \\ \mathrm{C}_{2} & 0\end{array}\right)$ is full column rank

$$
\Leftarrow \text { (iv) } \operatorname{rank}\left(\begin{array}{cc}
\mathrm{sI}_{\mathrm{n}}-\mathrm{A} & \mathrm{H} \\
\mathrm{C}_{2} & 0
\end{array}\right)=\mathrm{n}+\mathrm{q} \forall \mathrm{s} \in \mathrm{C}, \operatorname{Re}(\mathrm{s})>0 \text { • }
$$

Proof. The necessary and sufficient condition for the unknown input observer has already been proved by several authors as Kudva (1980), Hou and Muller (1992). The equivalence between the three propositions was proved by Darouach et al. (1994). The result is simply applied to our case and the complete proof is therefore omitted because of the number of pages required for this paper. Note that (iii) stands for the necessary and sufficient condition of existence for the parity space under Hyp. 1, 2, 3.

The indirect residual is given by the output reconstruction error:

$$
\mathrm{e}(\mathrm{t})=\mathrm{y}_{2}(\mathrm{t})-\hat{\mathrm{y}}_{2}(\mathrm{t})=\mathrm{y}_{2}(\mathrm{t})-\mathrm{C}_{2} \hat{\mathrm{x}}(\mathrm{t})-\mathrm{D}_{2} \mathrm{u}(\mathrm{t})
$$

within the model (3.c) and can be expressed such as:

$$
\begin{aligned}
e(s) & \left.=-\left[C_{2}\left(s I_{n}-N\right)^{-1} G+C_{2} M+D_{2}\right]\right](s) \\
& -C_{2}\left(s I_{n}-N\right)^{-1} L_{1} y_{1}(s) \\
& +\left[I_{p-m}+C_{2} V_{2}-C_{2}\left(s I_{n}-N\right)^{-1} L_{2}\right]_{2}(s)
\end{aligned}
$$

\section{STRUCTURAL EQUIVALENCE}

Theorem 1. Consider system (1) of reduced form (3) that satisfies hypothesis 1,2 and 3. Consider the indirect residual (14) based on the unknown input observer (11).

Then, for any stable matrix $\mathrm{T}(\mathrm{s})$, the signal $\mathrm{r}(\mathrm{s})$ based on the expression:

$\mathrm{r}(\mathrm{s})=\mathrm{T}(\mathrm{s}) \mathrm{e}(\mathrm{s})$

is the direct residual based on the parity space defined by the projection matrix $\Omega(\mathrm{s})$ (7.a) where $\Omega_{3}(\mathrm{~s})$ is:

$$
\Omega_{3}(\mathrm{~s})=\mathrm{T}(\mathrm{s})\left[\mathrm{I}_{\mathrm{p}-\mathrm{m}}+\mathrm{C}_{2} \mathrm{~V}_{2}-\mathrm{C}_{2}\left(\mathrm{sI} \mathrm{I}_{\mathrm{n}}-\mathrm{N}\right)^{-1} \mathrm{~L}_{2}\right] \text { (16) }
$$

Proof. First, lemma 3 ensure the existence of the UIO. Therefore, from lemma 1, the existence condition of the parity space is also satisfied. Second, let choose $\Omega(\mathrm{s})$ of form (7.a) with the special choice (16) of $\Omega_{3}(\mathrm{~s})$. This choice must respect constraint (7.b). This is simply proved using (12.f), (12.h) and (12.c). Finally, it is quite simple to rewrite $\mathrm{r}(\mathrm{s})$ as (15) basing our demonstration on relations (12). For more details, see the proof of the theorem in (Nuninger, et al., 1996).

This theorem proves that if one knows an UIO for system (1) then, within the choice of a stable matrix $\mathrm{T}(\mathrm{s})$, it is easy to generate a direct residual $\mathrm{r}(\mathrm{s})$ based on the indirect residual $\mathrm{r}(\mathrm{s})$. Besides, one knows how to construct the corresponding parity space. Such residuals are called : dual residuals. What about the reciprocal ?

Theorem 2. Consider system (1) of reduced form (3) that satisfies hypothesis 1 and 2. Consider the direct residual (10) based on the parity space (7) where matrix $\Omega_{3}(\mathrm{~s})$ is given of dimension $(n+q) x(n+p)$.

Choose two matrices :

- a square stable matrix $\mathrm{N}$ of dimension $\mathrm{nxn}$,

- a constant matrix $\mathrm{V}_{20}$ of dimension $\mathrm{nx}(\mathrm{q}-\mathrm{m})$.

Then an UIO of form (11) defined by:

$\mathrm{V}_{2}=-\mathrm{H}_{2}\left(\mathrm{C}_{2} \mathrm{H}_{2}\right)^{+}+\mathrm{V}_{20}\left[\mathrm{I}-\left(\mathrm{C}_{2} \mathrm{H}_{2}\right)^{+}\left(\mathrm{C}_{2} \mathrm{H}_{2}\right)\right]$

$P$ defined by (12.f) and $L_{2}$ by :

$\mathrm{L}_{2}=\mathrm{K}-\mathrm{NV}_{2}$

where $\mathrm{K}$ satisfies the pole placement of $\left(\mathrm{PA}_{1}, \mathrm{C}_{2}\right)$ :

$\mathrm{PA}_{1}-\mathrm{KC}_{2}=\mathrm{N}$

and the defined matrices $M$ (12.d), G (12.h), $\mathrm{L}_{1}$ (12.e) and $V_{1}(12 . b)$ exists if and only if hypothesis 3 is true.

Besides, the signal $\mathrm{e}(\mathrm{t})$ generated by:

$$
\begin{aligned}
& \mathrm{e}(\mathrm{s})=\varphi(\mathrm{s}) \mathrm{r}(\mathrm{s}) \\
& \varphi(\mathrm{s})=\left[\mathrm{C}_{2}\left(\mathrm{sI}_{\mathrm{n}}-\mathrm{N}\right)^{-1} \mathrm{P}\left(\mathrm{sI}-\mathrm{A}_{1}\right) \mathrm{C}_{2}^{-}\right](\mathrm{s})
\end{aligned}
$$


is the indirect residual based on the previously defined unknown input observer if and only if $\mathrm{T}(\mathrm{s})$ is a stable matrix such that:

$\mathrm{T}(\mathrm{s}) \Omega_{3}(\mathrm{~s})=\mathrm{I}_{\mathrm{n}+\mathrm{p}}$

Proof. Note that $(.)^{+}=(.)^{\mathrm{T}}\left[(.)(.)^{\mathrm{T}}\right]^{-1}$ stands for the right inverse of the given matrix and

$(.)^{-}=\left[(.)^{\mathrm{T}}(.)\right]^{-1}(.)^{\mathrm{T}}$ for the left inverse. The proof is made in two steps. First, the existence of the UIO is proved. Second, the comparison of both residuals leads to (20) within constraint (21).

Step 1: From lemma 1, the UIO exists if and only if assumption 3 is true. Under these assumptions, the choice of $P$ (12.f) where $V_{2}$ is imposed by the choice of $\mathrm{V}_{20}$ like (17) ensure, from lemma 3, the existence of the UIO. Therefore, the observability of the pair $\left(\mathrm{PA}_{1}, \mathrm{C}_{2}\right)$ is satisfied. $\mathrm{K}$ can then be found within the choice of $\mathrm{N}$. $\mathrm{L}_{2}$ satisfies (18) and the remaining 
matrices $\mathrm{M}, \mathrm{G}, \mathrm{L}_{1}$ and $\mathrm{V}_{1}$ are then given by the expressions (12.d), (12.h), (12.e) and (12.b).

Step 2: Let us now rewrite e(s) so that expression (10) of $\mathrm{r}(\mathrm{s})$ appears in (14). Replace $\mathrm{M}, \mathrm{L}_{1}$ and $\mathrm{G}$ by their expressions in equation (14) to get:

$\mathrm{e}(\mathrm{s})=-\alpha(\mathrm{s}) \mathrm{u}(\mathrm{s})-\beta(\mathrm{s}) \mathrm{y}_{1}(\mathrm{~s})+\gamma(\mathrm{s}) \mathrm{y}_{2}(\mathrm{~s})$

where:

$\alpha(s)=C_{2}\left(s_{n}-N\right)^{-1}\left[\mathrm{~PB}_{1}-\mathrm{L}_{2} \mathrm{D}_{2}\right]+\mathrm{C}_{2} \mathrm{~V}_{2} \mathrm{D}_{2}+\mathrm{D}_{2}$

$\beta(\mathrm{s})=\mathrm{C}_{2}\left(\mathrm{sI}_{\mathrm{n}}-\mathrm{N}\right)^{-1} \mathrm{PH}_{1}$

$\gamma(\mathrm{s})=\left[\mathrm{I}_{\mathrm{p}-\mathrm{m}}+\mathrm{C}_{2} \mathrm{~V}_{2}-\mathrm{C}_{2}\left(\mathrm{sI}_{\mathrm{n}}-\mathrm{N}\right)^{-1} \mathrm{~L}_{2}\right]$

Let us now introduce $\mathrm{I}=\mathrm{C}_{2} \mathrm{C}_{2}^{-}$where $\mathrm{C}_{2}^{-}=\mathrm{C}_{2}^{\mathrm{T}}\left(\mathrm{C}_{2} \mathrm{C}_{2}^{\mathrm{T}}\right)^{-1}$ which exists and further replace $\mathrm{V}_{2} \mathrm{C}_{2}$ by its expression (12.f). Within factorisation of the term $\mathrm{C}_{2}\left(\mathrm{sI}_{\mathrm{n}}-\mathrm{N}\right)^{-1}, \alpha(\mathrm{s})$ and $\gamma(\mathrm{s})$ are expressed by:

$\alpha(s)=C_{2}\left(s_{n}-N\right)^{-1}\left[\mathrm{~PB}_{1}-L_{2} D_{2}+\left(\mathrm{sI}_{\mathrm{n}}-\mathrm{N}\right) \mathrm{PC}_{2}^{-} \mathrm{D}_{2}\right]$

$\gamma(\mathrm{s})=\mathrm{C}_{2}\left(\mathrm{sI}_{\mathrm{n}}-\mathrm{N}\right)^{-1}\left[\left(\mathrm{sI}_{\mathrm{n}}-\mathrm{N}\right) \mathrm{PC}_{2}^{-}-\mathrm{L}_{2}\right]$

The product NP is then replaced by (12.g). After factorisation by $\mathrm{P}\left(\mathrm{sI}_{\mathrm{n}}-\mathrm{A}_{1}\right)$ the following expressions are obtained:

$$
\begin{aligned}
& \alpha(s)=C_{2}\left(s I_{n}-N\right)^{-1} P\left(s I_{n}-A_{1}\right)\left[\left(s_{n}-A_{1}\right)^{-1} B_{1}+C_{2}^{-} D_{2}\right] \\
& \beta(s)=C_{2}\left(s I_{n}-N\right)^{-1} P\left(s I_{n}-A_{1}\right) P\left[\left(s I_{n}-A_{1}\right)^{-1} H_{1}\right] \\
& \gamma(s)=C_{2}\left(s I_{n}-N\right)^{-1} P\left(s I_{n}-A_{1}\right)\left[C_{2}^{-}\right]
\end{aligned}
$$

Finally, define $\zeta(\mathrm{s})$ so that (23) is true. Therefore $\alpha(\mathrm{s})$, $\beta(\mathrm{s})$ and $\gamma(\mathrm{s})$ are given by (24) :

$$
\begin{aligned}
& \zeta(s) C_{2}=C_{2}\left(s I_{n}-N\right)^{-1} P\left(s I_{n}-A_{1}\right) \\
& \alpha(s)=\zeta(s)\left[\left(s I_{n}-A_{1}\right)^{-1} B_{1}+D_{2}\right] \\
& \beta(s)=\zeta(s)\left[C_{2}\left(s I_{n}-A_{1}\right)^{-1} H_{1}\right] \\
& \gamma(s)=\zeta(s)
\end{aligned}
$$

It is obvious, from the comparison of (22) and (10) that:

$$
\mathrm{e}(\mathrm{s})=\zeta(\mathrm{s}) \mathrm{T}(\mathrm{s}) \mathrm{r}(\mathrm{s})
$$

is true if and only if the stable matrix $\mathrm{T}(\mathrm{s})$ satisfies condition (21). Definition (23) of $\zeta(s)$, implies:

$\zeta(\mathrm{s})=\mathrm{C}_{2}\left(\mathrm{sI}_{\mathrm{n}}-\mathrm{N}\right)^{-1} \mathrm{P}\left(\mathrm{sI}_{\mathrm{n}}-\mathrm{A}_{1}\right) \mathrm{C}_{2}^{-}$.

From (25), (20.a) is true with $\varphi(\mathrm{s})=\zeta(\mathrm{s}) \mathrm{T}(\mathrm{s})$

Thanks to this theorem, the knowledge of a direct residual and the projection matrix that defines the corresponding parity space allows, for a special design of the UIO, to generate the dual indirect residual quite easily. This theorem is the reciprocal of theorem 1 but it is important to note that the UIO observer only exists if assumption 3 is true. Besides, in that case, T(s) must satisfies the stronger constraint (21).

\section{DISCUSSION}

From theorems 1 and 2, it is always possible to get a dual direct residual of an indirect one but the contrary is not always true. Besides, when it is possible, a stronger constraint (21) must be satisfied by $\mathrm{T}(\mathrm{s})$. The reciprocal does not require such a condition as the design of the observer is already imposed and a total freedom for the choice of $\Omega_{3}(\mathrm{~s})$ is allowed. Therefore, it is simpler to get the direct residual. These results are illustrated in Fig. 2 where $\mathrm{O}$ stands for a set of solutions within the indicated hypothesis and the transfer law ' $\rightarrow$ ' are given with the constraints.

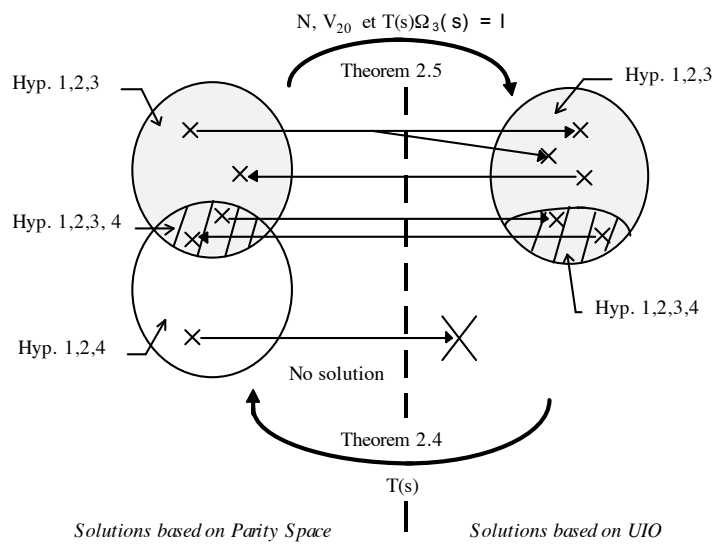

Fig. 2: Transfer law between direct and indirect residuals.

So one may think that detection systems based on both approaches are strictly equivalent under some hypothesis. In fact, one can not conclude so easily. Indeed, robustness performance of both residuals has to be considered, even though the residuals are structurally equivalent. First, it is necessary to make a proper choice of the observer gain. Indeed, this gain should further allow detection and isolation of the faults within the residual. From theorem 1, any stable matrix $\mathrm{T}(\mathrm{s})$ can a priori be chosen. As a consequence the residual e(s) generated from (15) can not be a priori influenced by certain faults. Therefore, good performances of the fault detection and isolation system could not a priori be achieved. Nevertheless, from theorem 1, it is possible to improve the robustness of the indirect residual if a good choice for $\mathrm{T}(\mathrm{s})$ is made. As a consequence, it seems simpler to directly design the fault detection system by the parity space approach in order to get a good degree of robustness. This result has also been advanced by Frank (1990). From theorem 2 , it is obvious that the design of the UIO is more constrained if one wants to apply equation (20.a) because of the constraint (21). Anyway, theorem 2 allows us to design quite easily the observer and get the 
residual however it can be useless for fault detection and isolation. These theorems also show that the direct approach is a better one, as it is easier to construct the parity space taking into account the robustness constraints with respect to systems uncertainties. Indeed, it is simpler to get structured or fixed direction residuals that will increase the degree of robustness. Nevertheless, it is important to note that however there exists a minimal degree for the projection matrix (Nuninger, et al., 1996), in practice the numeric implementation is not always possible. Indeed, because of inconsistencies, the exact solution $\Omega_{3}(\mathrm{~s})$ might not be found that satisfies the constraint (9). Therefore, suboptimal solutions should be performed in order to satisfy the independence of some state and unknown input components. Of course, this implies a degradation of the performance. On the contrary, the observer based method can be interesting using a generalised observer scheme.

Finally, both theorems can be applied to find, for a given residual based on parity space (observer) the corresponding design of the unknown input observer (parity space) that leads to the same residual: i.e. $\mathrm{e}(\mathrm{s})=\mathrm{r}(\mathrm{s})$. Considering theorem 1 , the special choice of $\mathrm{T}(\mathrm{s})$ equal to the identity matrix is obvious. On the contrary, the constraint on $\mathrm{N}$ and $\mathrm{V}_{20}$ is harder to satisfy. Indeed, theses matrices are defined so that:

$\mathrm{C}_{2}\left(\mathrm{sI}_{\mathrm{n}}-\mathrm{N}\right)^{-1} \mathrm{P}\left(\mathrm{sI}_{\mathrm{n}}-\mathrm{A}_{1}\right) \mathrm{C}_{2}^{-}=\Omega_{3}(\mathrm{~s})$

With respect to the diagnostic procedure, the given theorems prove that an optimal solution does not always exists based on UIO whereas a solution can always be given based on parity space approach

(Hyp. 4 true but not Hyp. 3). Therefore, parity space approach seems more convenient to achieve a higher degree of robustness. Note that this remark does not mean that this solution can not be found within UIO when such an observer exists.

\section{CONCLUSION}

This paper has focused the structural equivalence of residuals based on two a priori different methods using analytical redundancy: parity space and observers. This equivalence is well known in the literature but this paper considers the case of unknown input observer based residuals. This paper is the following of (Nuninger, et al., 1996) as the reciprocal theorem is given, proving that both residuals can be obtained from the other one, within little assumptions, thanks to their structural equivalence through a transfer function. The relevance of this work is that one can now conclude that the parity space approach seems to be the simplest way to take into account robustness constraints with respect to systems disturbances. Moreover, it is simpler to get the direct residual from the one based on the UIO (theorem 1) than the reciprocal that requires a more restrictive assumption on $\mathrm{T}(\mathrm{s})$ (theorem 2). In the future, the effect of model uncertainties on the two dual residuals should be discussed and compared within the structure of $\mathrm{T}(\mathrm{s})$, which is in fact a filter between both residuals. The aim is to stress on the statistical proprieties in order to emphasise which one of the dual residuals is the more valuable with respect to robustness. It is then obvious that the choice of the matrix $\mathrm{T}(\mathrm{s})$ is quite important in that matter.

\section{REFERENCES}

Darouach, M., M. Zasadzinski and S.J. Xu (1994). Full-order observers for linear systems with unknown inputs. IEEE Trans. on Automatic Control, 39 (3), pp. 606-609.

Frank, P.M. and I. Wünnenberg (1989). Robust fault diagnosis using unknown input observer schemes. In: Fault Diagnosis in Dynamic Systems (R. Patton, P.M. Frank and R. Clark, Ed.), pp. 47-97. Prentice Hall.

Frank, P.M. (1990). Fault diagnosis in dynamic systems using analytical and knowledge base redundancy - A survey and some new results. Automatica, 26 (3), pp. 459-474.

Frank, P.M. (1993). Advances in observer-based fault diagnosis. Tooldiag'93, Inter. Conf. on Fault Diagnosis, pp 817-836.

Gantmacher, F.R. (1977). The theory of matrices. Chelsea Publishing Company.

Gertler, G. (1991). Analytical redundancy in fault detection and isolation. SAFEPROCESS'91, pp. 9-22.

Hou, M. and P.C. Müller (1992). Design of observers for linear systems with unknown inputs. IEEE Trans. on Automatic Control, 37(6), pp. 871-875.

Iserman, R. (1984). Process fault detection based on modelling and estimation methods, Automatica, 20 (4), pp. 387-404.

Kudva, P., N. Viswanadham and A. Ramakrishanan (1980). Observers for linear systems with unknown inputs. IEEE Trans. on Automatic Control, 25(1), pp. 113-115.

Magni, J.F. and Mouyon Ph. (1991). A generalized approach to observers for fault diagnosis, 30th IEEE Conference on Decision and Control, $\mathbf{3}$, pp. 2236-2241.

Nuninger, W., F. Kratz and J. Ragot (1996). Observers and redundancy equations generation for systems with unknown inputs. CESA'96, Symposium on Control, Optimization and Supervision, 1, pp. 672-677.

Patton, R.J. and J. Chen (1991). A parity space approach to robust fault detection using eigenstruture assignment, European Control Conference, pp. 1419-1424.

Patton, R.J. (1994); Robust model-based fault diagnosis: the state of art. SAFEPROCESS'94, pp. 1-24.

Staroswiecki, M. (1991). Generation of analytical redundancy relations in a linear interconnected system. In: 
Mathematical and Intelligent Models in System Simulation (J.C. Boltzer, Ed.),

pp. 391-396. Scientific Publishing, IMACS.

Wunnenberg, I. (1990). Observer-based fault detection in dynamic systems, $P h D$, Duisbourg. 